\title{
Improvement of In vitro Release of Glibenclamide Using Cyclodextrin Inclusion Complexation
}

\author{
Neelkant Prasad ${ }^{1}$, Navneet Garud ${ }^{2}$ and Akanksha Garud ${ }^{3}$ \\ ${ }^{1}$ Dr. K. N. Modi Institute of Pharmaceutical Education and Research, Modinadar (U.P.) \\ ${ }^{2}$ School of Studies in Pharmaceutical Sciences, Jiwaji University, Gwalior (M.P.), India \\ ${ }^{3}$ Department of Pharmaceutics, Institute of Professional Studies- College of Pharmacy Gwalior (M.P.), India
}

Received: July 15, 2012; Accepted: November 07, 2013; Published (web): June 29, 2014

\begin{abstract}
The present study aimed to improve the aqueous solubility of the oral hypoglycemic agent, glibenclamide (GLI), so as to improve its oral absorption, and hence bioavailability after oral administration. This was accomplished by complex formation between GLI and $\beta$-cyclodextrin ( $\beta$-CD). The study involves the preparation of the inclusion complexes using different techniques. Differential Scanning Calorimetry (DSC) and XRay Diffractometry (XRD) results confirmed the complex formation between GLI and $\beta$-CD. The solubility increase of GLI was due to 1:1 complex formation. The dissolution rate of GLI from the complex prepared by neutralization method was more rapid as compared to other methods used.
\end{abstract}

Key words: Glibenclamide, $\beta$-cyclodextrin, Inclusion complex, Neutralization method, Co-precipitation.

\section{INTRODUCTION}

Glibenclamide (GLI) is a potent oral hypoglycemic agent from the second generation sulphonyl ureas used in the treatment of type II diabetes mellitus (DM). It is practically insoluble in water with very poor in vitro dissolution. This results in low bioavailability of the drug with only $45 \%$ of the drug being absorbed through the gastrointestinal tract on oral administration ${ }^{1}$. Therefore, the dissolution of GLI is considered to be the rate limiting step for its absorption. Increasing the solubility of GLI was earlier attempted by several methods using solid dispersion ${ }^{2}$, surface active agents $^{3}$, glass formation ${ }^{4}$ and coadministration of water-soluble polymers such as hydroxylropylmethylcellulose (HPMC). ${ }^{5}$ Coadministration of water-soluble polymers with the drug-CD complex has increased the efficiency of $\mathrm{CD}$ in increasing the aqueous solubility of GLI with using minimal amount of $\mathrm{CD}^{5}$. For a series of reasons, including price, availability, approval status and cavity dimensions, $\beta$ $\mathrm{CD}$ is most widely used in inclusion complex formation.

Correspondence to: Neelkant Prasad

Email: prasadneelkant@gmail.com

Dhaka Univ. J. Pharm. Sci. 13(1): 15-21, 2014 (June)
In the present study, enhancement of the solubility and dissolution rate of GLI was attempted by complexation with $\beta$-CD. Physical characteristics of the solid form of this formulation were examined by infrared spectroscopy (IR) and X-ray diffraction (XRD). Phase solubility and dissolution studies were conducted to examine the release of the drug. Different preparation techniques, such as kneading method, neutralization method and co-precipitation, were used to prepare, characterize and determine the effect of different GLI- $\beta$-CD complexes on aqueous solubility and in-vitro dissolution studies.

\section{MATERIALS AND METHODS}

Glibenclamide (GLI) was obtained as a gift sample from Zydus Cadila, Ahmedabad, India and $\beta$ Cyclodextrin ( $\beta-C D)$ was procured from Loba Chemie Pvt. Ltd, Bangaluru, India. All other chemicals were of analytical grade and were used as supplied.

\section{Preparation of the complexes}

Kneading method ${ }^{6}$. GLI and $\beta-C D$ in molar ratios of $1: 1$ and $1: 2$ were prepared by kneading method. Here, $\beta$-CD was triturated with purified 
water in a mortar to obtain a paste then the drug was added and mixed for 30 minutes followed by drying in an oven at $40^{\circ} \mathrm{C}$ till constant weight was obtained.

Neutralization method ${ }^{7}$. About $25 \mathrm{mg}$ of GLI was accurately weighed and dissolved in $50 \mathrm{ml}$ of $0.005 \mathrm{~N}$ sodium hydroxide solution followed by respective amount of $\beta$-CD. The mixture was then placed on a magnetic stirrer and stirred until a clear solution was obtained. $50 \mathrm{ml}$ of $0.005 \mathrm{~N}$ hydrochloric acid was then added dropwise followed by stirring for 2 hours. The inclusion complex, so formed, was filtered by Whatman filter paper No. 41, washed repeatedly and dried at room temperature.

Co-precipitation ${ }^{8}$. The calculated amount of GLI was added in similar ratios to $\beta$-CD dissolved in $50.0 \mathrm{ml}$ water followed by shaking at room temperature for 72 hours. The product was obtained by filtration by Whatman filter paper No. 41 followed by drying at room temperature.

Table 1. Formulation design of inclusion complexes

\begin{tabular}{cccc}
\hline $\begin{array}{c}\text { Formulation } \\
\text { Code }\end{array}$ & $\begin{array}{c}\text { Drug : } \beta \text {-CD } \\
\text { molar ratio }\end{array}$ & Method of Preparation & Kneading Agent \\
\hline SD1 & $1: 1$ & Kneading method & Water \\
SD2 & $1: 2$ & Kneading method & Water \\
SD3 & $1: 2$ & Co-precipitation Method & - \\
SD4 & $1: 2$ & Kneading method & Alcohol \\
SD5 & $1: 2$ & Neutralization Method & - \\
\hline
\end{tabular}

Characterization of the mixtures and inclusion complexes

Phase solubility studies. ${ }^{9}$ The phase solubility studies were performed according to Higuchi and Connors method (1965). An excess amount from the formulation or the drug was transferred to $20 \mathrm{ml}$ screw capped glass bottles to which $10 \mathrm{ml}$ of phosphate buffer ( $\mathrm{pH}$ 7.4) was added. Different molar concentrations of $\beta-C D$ were added to excess amount of GLI. The mixtures were shaken in a water bath at $37 \pm 0.5{ }^{\circ} \mathrm{C}$ for $72 \mathrm{hr}$. All samples were filtered through Whatman filter paper, and analyzed for GLI at $300 \mathrm{~nm}$ by UV spectrophotometer (Shimadzu 1601, Japan).

Powder X-ray diffractometry. The powder Xray diffraction patterns were recorded using a Siemens Kristallofex D-5000 diffractometer (Siemens, Munich, Germany), with $\mathrm{Cu}$ as anode material and crystal graphite monochromator, operated at a voltage of $40 \mathrm{kV}$ and a current of 30 $\mathrm{mA}$. The samples were analyzed in the $2 \theta$ angle range of $3-40^{\circ}$. The process parameters used were: step size of $0.045^{\circ}(2 \theta)$, scan step time of 0.5 seconds, and time of acquisition of 2 hours.

FTIR Spectra. The FTIR spectra of GLI and its complexes were obtained using FTIR
Spectrophotometer (JASCO- 4100, Japan) and compared. Spectra were obtained by potassium bromide disc technique.

Content uniformityl. ${ }^{10}$ The content uniformity was determined as per Indian Pharmacopoeia (IP) 1996. The formulation was warmed with $10 \mathrm{ml}$ of 0.1 M methanolic hydrochloric acid and centrifuged using laboratory centrifuge. The extraction was repeated thrice with three further quantities, each of $10 \mathrm{ml}$, of $0.1 \mathrm{M}$ methanolic hydrochloric acid. The combined extracts were cooled and sufficient $0.1 \mathrm{M}$ methanolic hydrochloric acid was added to produce $50.0 \mathrm{ml}$. The absorbance of the resulting solution was measured at $300 \mathrm{~nm}$ using UV spectrophotometer (Shimadzu 1601, Japan). The content of GLI was calculated by taking 63 as the specific absorbance at $300 \mathrm{~nm}$.

In vitro dissolution studies. ${ }^{11}$ In vitro dissolution of GLI was assessed at $37 \pm 0.5^{\circ} \mathrm{C}$ by the USP Dissolution Tester, Apparatus I (Rotating basket), using $900 \mathrm{ml}$ phosphate buffer ( $\mathrm{pH}=7.4$ ) as the dissolution medium and at a rotation speed of 75 rpm. Briefly, $10 \mathrm{mg}$ GLI or an equivalent amount of GLI-processed complexes was transferred to the basket and dissolution was performed. Aliquots, each of $5 \mathrm{ml}$, from the dissolution medium were 
withdrawn after 5, 10, 15, 20, 30, 45, 60, 90, 120 and $180 \mathrm{~min}$ and replaced by an equal volume of fresh dissolution medium. The samples were withdrawn through a sintered glass filter and the GLI content was determined by measuring its absorbance at $300 \mathrm{~nm}$ using phosphate buffer $(\mathrm{pH}=7.4)$ as blank by UV spectrophotometer (Shimadzu 1601, Japan).

Statistical analysis. Experimental data was expressed as mean with standard deviation (SD) and the significance of differences was evaluated using analysis of variance (ANOVA). The differences were considered statistically significant at $p<0.05$.

\section{RESULTS AND DISCUSSION}

Phase solubility studies. A $B_{S}$ type of solubility curve was obtained (Higuchi and Connors, 1965). Btype phase-solubility profiles indicate formation of complexes with limited solubility in the aqueous medium. In general, the less soluble natural cyclodextrins frequently form B-type profiles. In a $\mathrm{B}_{\mathrm{S}}$ type phase solubility profile, the aqueous solubility of the drug initially increases with increase in concentration of complexing agent, and then practically no change in solubility is found for a short concentration range of the complexing agent followed by a decrease in drug concentration with increase in concentration of complexing agent. First, aqueous solubility of GLI increased linearly as a function of $\beta-C D$ concentration. Then a short plateau was reached followed by a decrease in total GLI and precipitation of crystalline complex. It was assumed that the solubility increase was due to the formation of $1: 1$ complex. The phase solubility curve is given in Figure 1

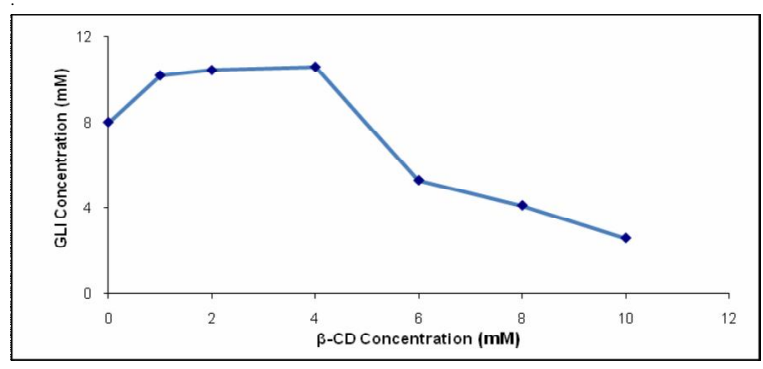

Figure 1. Phase solubility curve of GLI and $\beta-C D$

Evidences of complex formation. XRD and IR were employed on pure drug, pure $\beta-C D$, physical mixtures and the inclusion complexes and were compared. To confirm the complexation of GLI with $\beta$-CD in the solid state, XRD were employed and compared with pure drug. Three highest values for relative intensities, their corresponding scattering angles and interplaner $\mathrm{d}$-spacing values of drug, $\beta$ $\mathrm{CD}$ and the complexes were used as proof for inclusion complex formation. A difference of \pm 0.03 for the $d$ values implies a change in the crystal lattice of drug and $\beta-C D$. The X-ray diffractograms of GLI, $\beta-\mathrm{CD}$, inclusion complexes formed by kneading method (SD1 and SD2, having GLI: $\beta$-CD molar ratio of $1: 1$ and $1: 2$, respectively) and inclusion complexes formed by neutralization method were compared and are shown in Figure 2a-2e and Table 2.

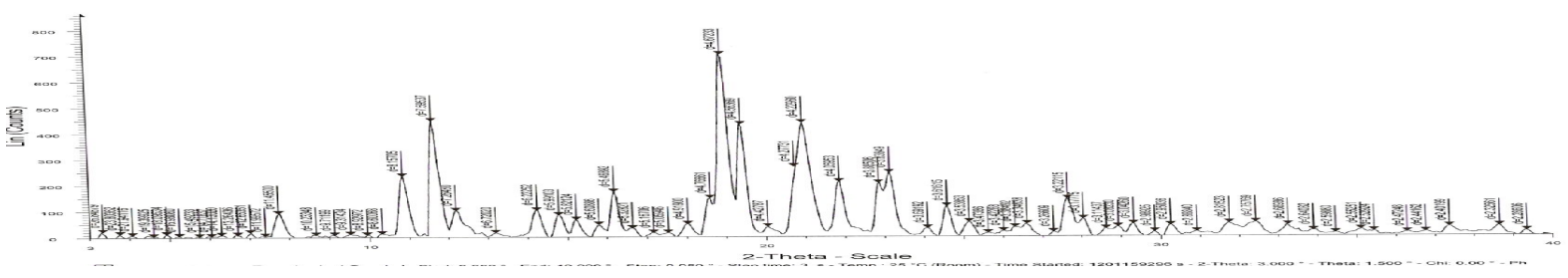

Figure 2a. X-ray diffraction pattern of pure GLI

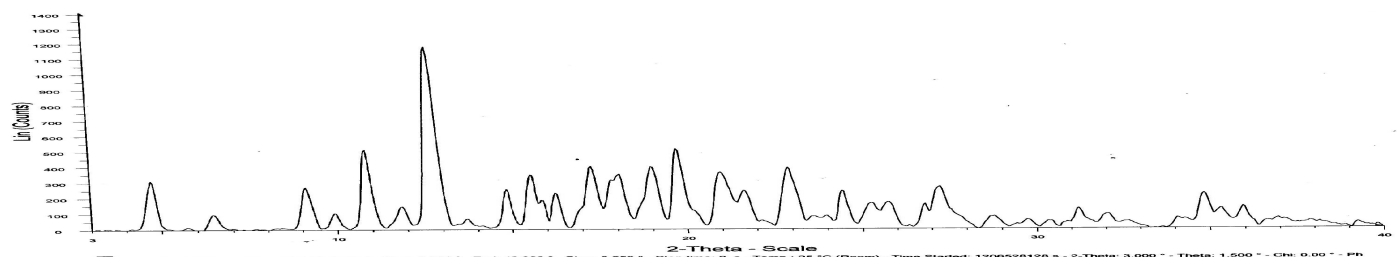

Figure $2 \mathrm{~b}$. X-ray diffraction pattern of pure $\beta$-CD 


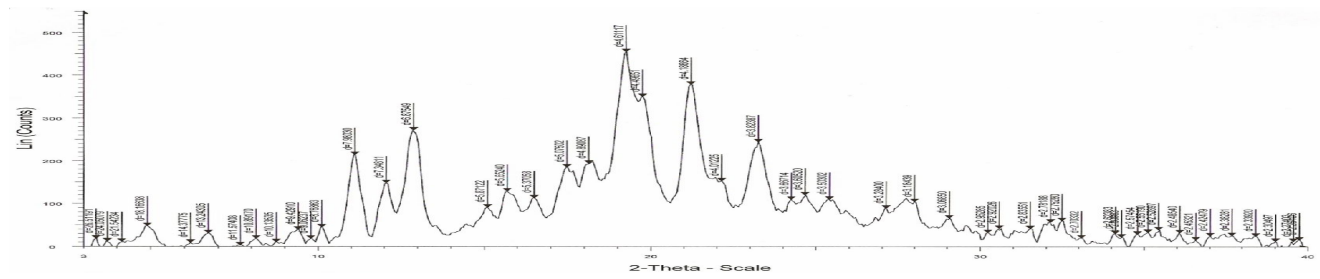

Figure 2c. X-ray diffraction pattern of inclusion complex SD1

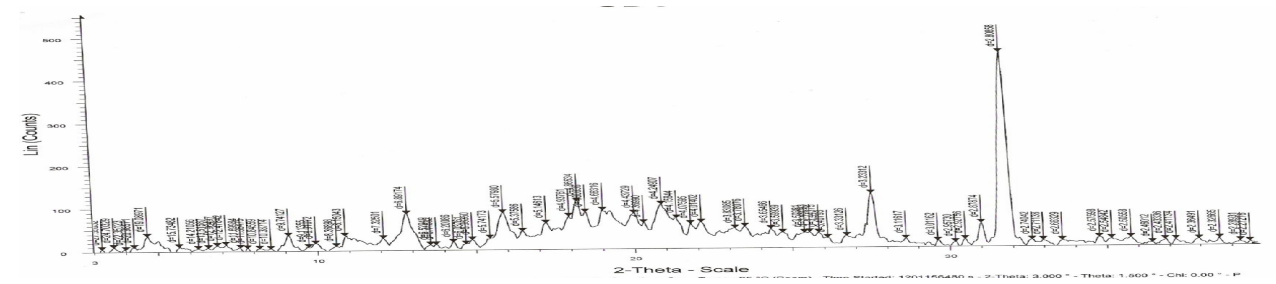

Figure 2d. X-ray diffraction pattern of inclusion complex SD2

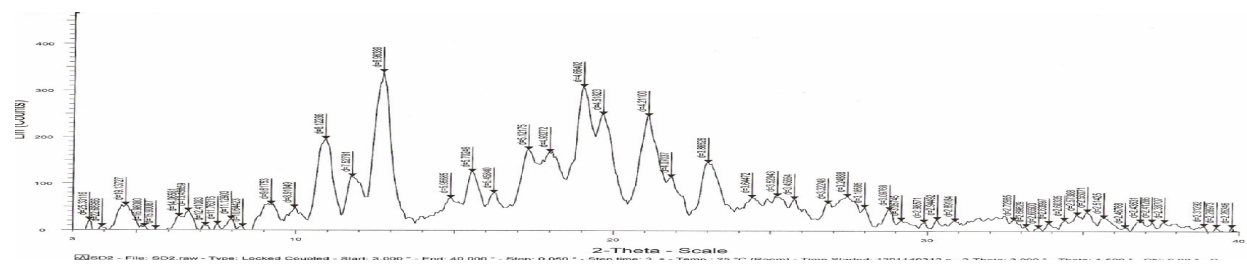

Figure 2e. X-ray diffraction pattern of inclusion complex SD5

Table 2. Data of $X$-ray diffraction patterns of pure drug, $\beta$-CD and various formulations showing evidence of inclusion complex formation

\begin{tabular}{|c|c|c|c|c|c|c|c|c|c|}
\hline \multirow[b]{2}{*}{ Product } & \multicolumn{3}{|c|}{ Peak 1} & \multicolumn{3}{|c|}{ Peak 2} & \multicolumn{3}{|c|}{ Peak 3} \\
\hline & $2 \theta$ & d-spacing & $\begin{array}{c}\mathrm{I} / \mathrm{I}_{\max }(\%) \\
\text { [Approx. } \\
\text { Counts] }\end{array}$ & $2 \theta$ & d-spacing & $\begin{array}{r}\mathrm{I} / \mathrm{I}_{\max }(\%) \\
\text { [Approx. } \\
\text { Counts] }\end{array}$ & $2 \theta$ & d-spacing & $\begin{array}{l}\mathrm{I} / \mathrm{I}_{\max }(\%) \\
\text { [Approx. } \\
\text { Counts] }\end{array}$ \\
\hline Pure GLI & 18.992 & 4.67233 & $100[700]$ & 11.670 & 7.59537 & $64[450]$ & 20.978 & 4.22960 & $63[440]$ \\
\hline$\beta-C D$ & 12.691 & 6.96952 & 100 [1200] & 10.821 & 8.16916 & $43[500]$ & 22.945 & 3.87288 & 33 [350] \\
\hline SD1 & 19.233 & 4.61117 & $100[450]$ & 21.204 & 4.18664 & 83 [370] & 12.865 & 7.34811 & $60[270]$ \\
\hline SD2 & 12.701 & 6.96389 & $100[330]$ & 19.013 & 4.66402 & 93 [300] & 21.080 & 4.21100 & 72 [240] \\
\hline SD5 & 31.833 & 2.80858 & $100[440]$ & 27.571 & 3.23312 & 28 [120] & 19.003 & 4.66316 & 20 [90] \\
\hline
\end{tabular}

The differences in $\mathrm{d}$ values confirm the formation of the complexes.

The functional groups of GLI involved in complexation were also involved in FT-IR. Spectra of pure GLI and its inclusion complexes with $\beta$-CD are shown in Figure 3a- 3e. The various peaks are compared in Table 3.

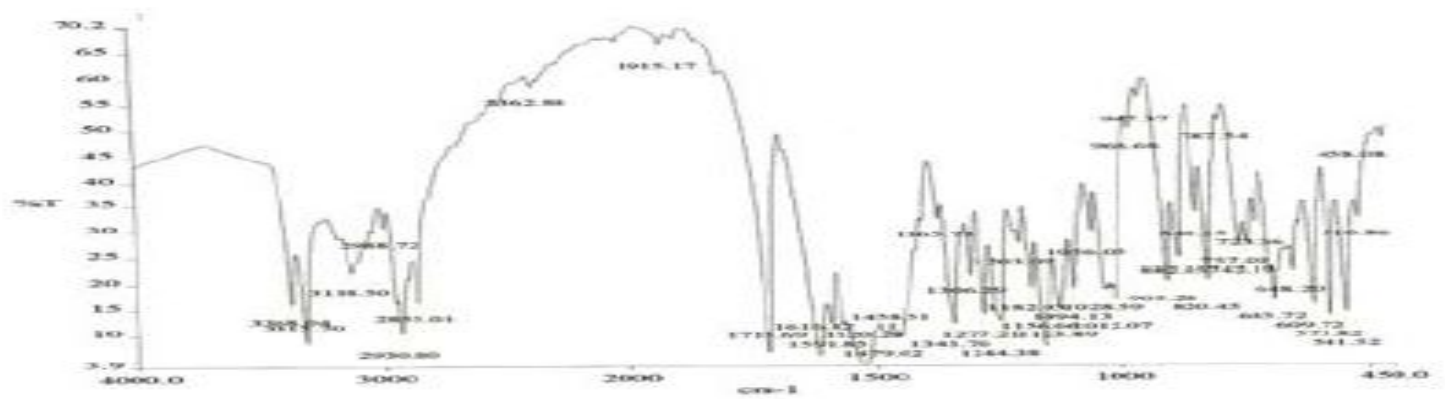

Figure 3a. FTIR spectrum of pure drug (GLI) 


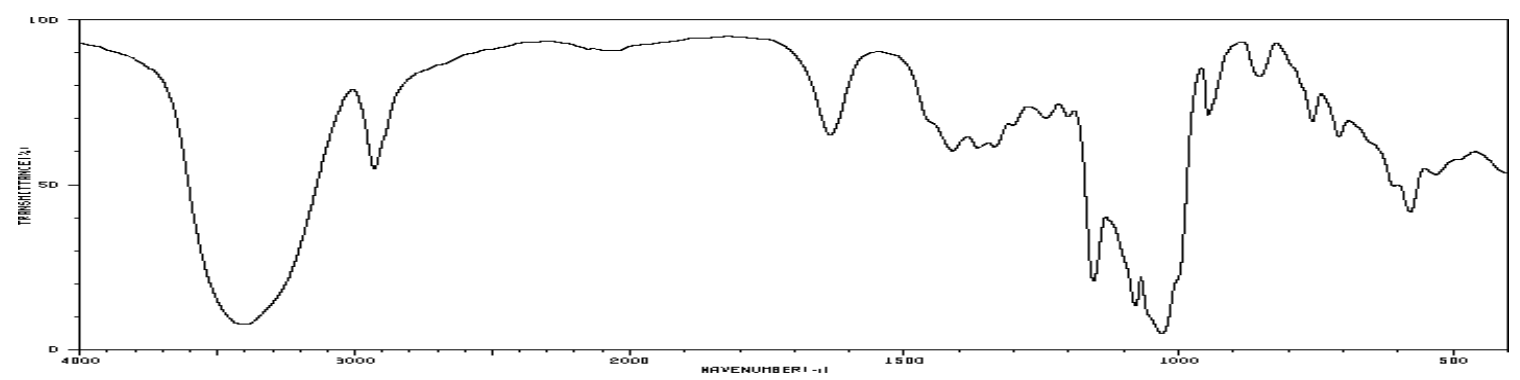

Figure $3 b$. FTIR spectrum of pure $\beta$-CD

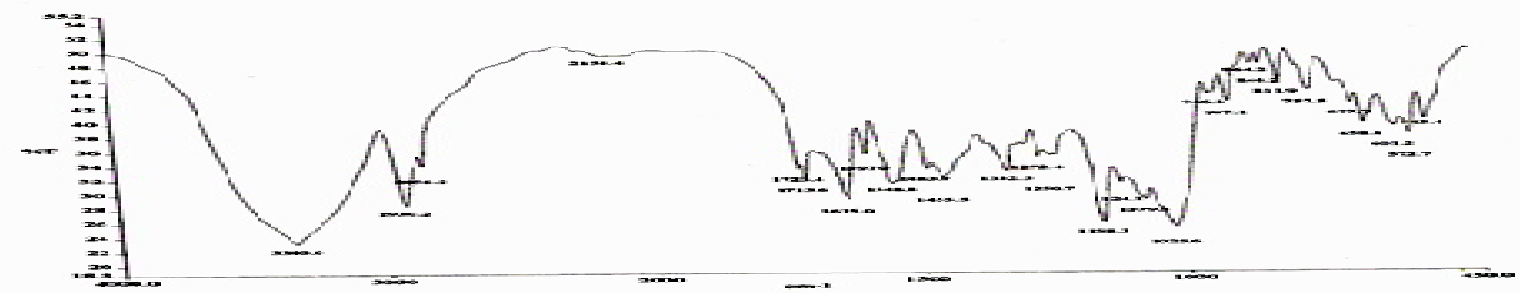

Figure 3c. FTIR spectrum of SD1

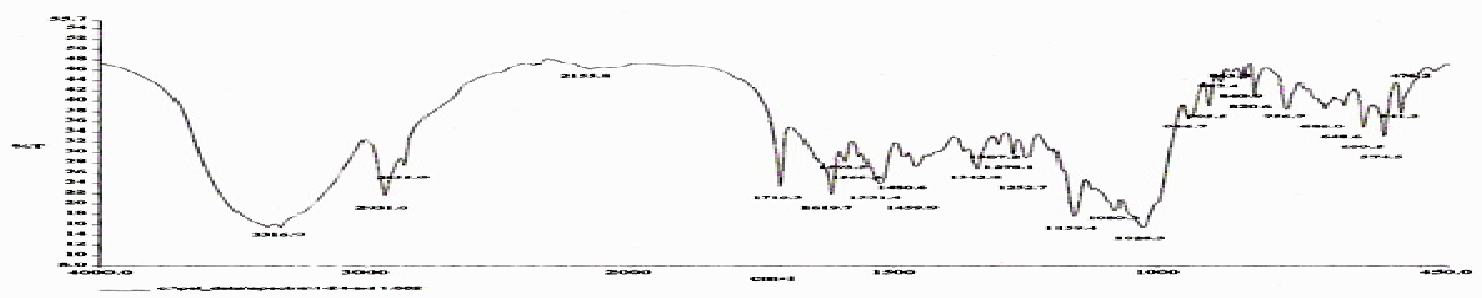

Figure 3d. FTIR spectrum of SD2

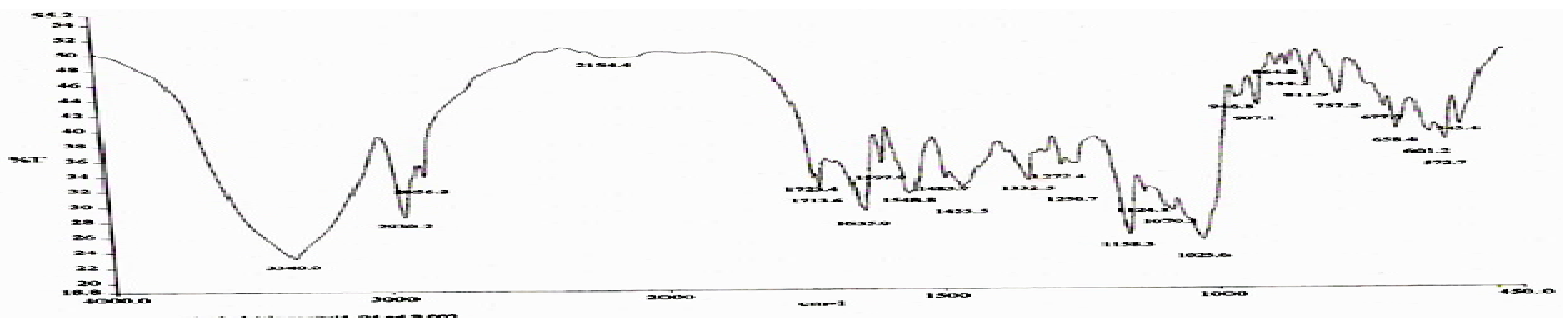

Figure 3e. FTIR spectrum of SD5

Table 3. FTIR spectra of pure drug, $\beta$-CD and inclusion complexes showing evidence of inclusion complex formation

\begin{tabular}{|c|c|c|c|c|c|}
\hline \multirow[t]{2}{*}{ Peak } & \multicolumn{5}{|c|}{ Wave no. $\left(\mathrm{cm}^{-1}\right)$} \\
\hline & GLI & $\beta-C D$ & SD1 & SD2 & SD5 \\
\hline $\mathrm{C}=\mathrm{O}$ in sulfonyl urea & 1714.60 & ---- & 1723.40 & 1716.30 & 1716.40 \\
\hline Secondary N-H Stretch in sulfonyl urea & 3315.41 & ---- & 3340 & 3316 & 3368 \\
\hline Symmetric $\mathrm{S}=\mathrm{O}$ stretch in sulfonyl urea & 1159.14 & ---- & 1159.40 & 1158.90 & 1158.30 \\
\hline Asymmetric $\mathrm{S}=\mathrm{O}$ stretch in sulfonyl urea & 1340.43 & ---- & 1342.80 & 1342.40 & 1332.5 \\
\hline Absorbance by hydrogen-bonded $\mathrm{OH}$ group & --- & 3446.56 & $\begin{array}{l}\text { Smoothin } \\
\text { involvem }\end{array}$ & $\begin{array}{l}\text { these peaks } \\
\text { H-Bonding }\end{array}$ & occur due to \\
\hline
\end{tabular}

The spectral pattern of physical mixtures corresponds simply to superposition of the IR spectra of the two components. The spectrum of the neutralized complex (1:1 molar ratio) showed the most noticeable complexation compared to other inclusion complexes as there was considerable 
differences when compared with those of pure drug. GLI showed broadening of IR signal corresponding to the N-H band at $3315 \mathrm{~cm}^{-1}$. The carbonyl stretching $\left(1714.60 \mathrm{~cm}^{-1}\right)$ band intensity was also reduced. The neutralization complexes showed shifting towards shorter frequency of $\mathrm{S}=\mathrm{O}$ symmetrical vibration $\left(1159.14-1158.30 \mathrm{~cm}^{-1}\right)$. The coprecipitation mixtures showed noticeable changes in IR spectra compared with that of pure drug which shows formation of the complex. They exhibited lower intensities in the 1714.60 and $1340.43 \mathrm{~cm}^{-1}$ peaks and broader peaks at $3316 \mathrm{~cm}^{-1}$. The peak at $1159.14 \mathrm{~cm}^{-1}$ shifted towards at lower frequency $\left(1158.90 \mathrm{~cm}^{-1}\right)$ with lesser intensities. Kneaded complexes exhibited minor changes in their IR spectra compared with that of pure drug, indicating weaker interaction of GLI with $\beta$-CD.

In vitro dissolution studies. In-vitro dissolution studies were conducted on pure drug and the formulations. The dissolution profiles of pure drug and different formulations are shown in Figure 4. It is evident from the figure that the inclusion complexation with $\beta$-CD showed faster rates than that of pure drug. The pure drug showed the lowest release rate and less than $50 \%$ of the drug was released in two hours followed by formulation made by kneading method with only about $75 \%$ drug release. However, use of water (in case of SD1) or alcohol (in case of SD4) as kneading agent had no significant effect on drug release. The percent release of the drug from the formulation made by coprecipitation (SD3) and neutralization (SD5) methods after $2 \mathrm{hr}$ were $83 \%$ and $93 \%$, respectively. This showed that the extent of dissolution was found to be affected by the method of preparation of the complexes along with the amount of $\beta$-CD. The improved dissolution rate of the prepared inclusion complex may be due to the increase in solubility as well as marked reduction in the crystallinity of GLI.

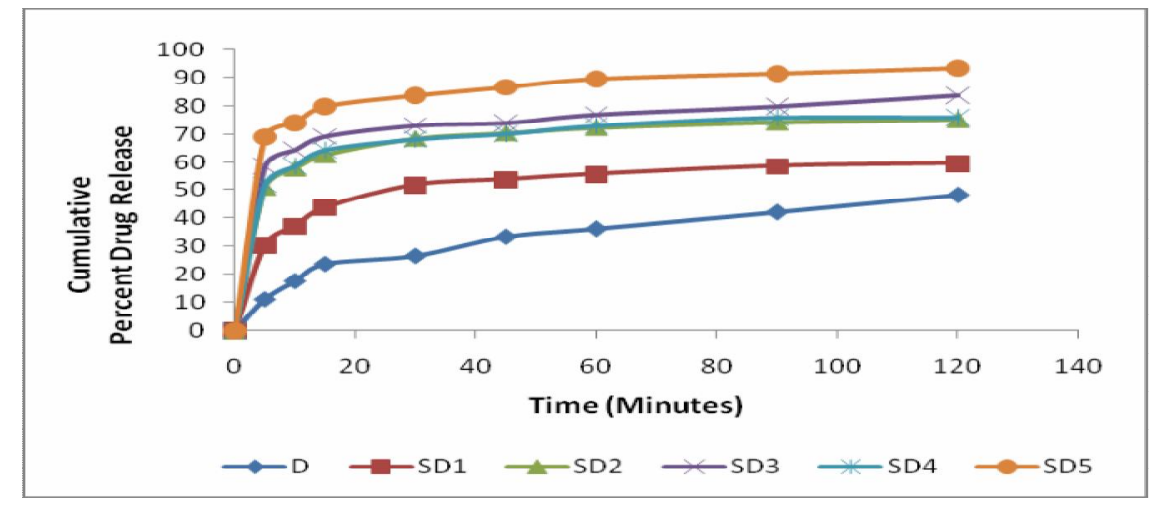

D- Pure drug (i.e., Glibenclamide)

Figure 4. In vitro dissolution profile of pure drug and inclusion complexes

\section{CONCLUSION}

From the dissolution data of all formulations developed, solubility of glibenclamide, a poorly water soluble drug was enhanced by complexation with $\beta-C D$ using different methods. The results indicate that complexation with neutralization method was the best in achieving in-vitro enhancement of glibenclamide dissolution characteristics.

\section{ACKNOWLEDGEMENT}

The authors wish to thank Dr S. K. Prajapati, Director, Institute of Pharmacy, Bundelkhand University Jhansi (U.P.), India for providing necessary facilities.

\section{REFERENCES}

1. Sanghavi, N.M., Venkastesh, H. and Tandel, V. 1994. Solubilization of glibenclamide with $\beta$-cyclodextrin and its derivatives. Drug Dev. Ind. Pharm. 20, 1275-1283. 
2. Tashtoush, B.M., Al-Qashi, Z.Z. and Najib, N.M. 2004. In vitro and in vivo evaluation of glibenclamide in solid dispersion systems. Drug Dev. Ind. Pharm. 30, 601-607.

3. Singh, J. and Singh, S. 1990. Physiological surfactants affecting permeation and BSL lowering in rabbits from Glibenclamide tablets. Drug Dev. Ind. Pharm. 16, 21932198.

4. Hassan, M., Najib, N. and Sulieman, M. 1991. Characterization of glibenclamide glassy state. Int. J. Pharm. 67, 131-137.

5. Savolainen, J., Jarvinen, K., Taipale, H., Jaho, P., Loftsson, T. and Jravinen, T. 1998. Co-administration of water-soluble polymer increases the usefulness of cyclodextrins in solid dosage forms. Pharm. Res. 15, 1696-1701.

6. Veiga, M.D. and Ahsan, F. 2000. Influence of surfactants (present in the dissolution media) on the release behaviour of tolbutamide from its inclusion complex with $\beta$-cyclodextrin Eur. J. Pharm. 9, 291-299.
7. Ozkan, Y., Atay, T. and Dikmen, N. 2000. Improvement of water solubility and in vitro dissolution rate of gliclazide by complexation with betacyclodextrin. Pharm. Acta Helv. 74, 365-370.

8. Hishman, S., Abou-Auda, Bawazir, S.A., Asiri, Y.A., Gubara, O.A. and Al-Hadiya, B.M. 2006. Study on solubility, bioavailability and hypoglycemic activity of gliclazide $\beta$ cyclodextrin complexes. Int. J. Pharmacol. 2, 656-663.

9. Higuchi, T. and Connors, K.A. 1965. Phase solubility techniques. Adv. Anal. Chem. 4, 117-212.

10. Indian Pharmacopoeia. The Controller of Publications, Delhi. 1996, Vol. I, 348

11. Reddy, M.N., Rehana, T., Ramakrishna, S., Chowdary, K.P.R. and Diwan, P.V. 2004. $\beta$-Cyclodextrin Complexes of Celecoxib: Molecular-Modeling, Characterization, and Dissolution Studies. AAPS Pharm. Sci. 6, Article 7. 